\title{
Wound Healing Effects of Arnebia Densiflora Root Extracts on Rat Palatal Mucosa
}

\author{
H.Huseyin Kosger \\ Mustafa Ozturk ${ }^{b}$ \\ Atalay Sokmen ${ }^{c}$ \\ Eray Bulut ${ }^{d}$ \\ Sinan Aye
}

\section{ABSTRACT}

Objectives: The aim of this study was to investigate wound healing effects of Arnebia densiflora (Nordm.) Ledeb. root extracts on rat palatal mucosa.

Methods: A $10-\mathrm{mm}$ full-thickness mucosal wounds were created on midline of rats' palate by using scalpel. In the experimental groups, a ten percent extract of $A$. densiflora roots was topically applied once a day as ointment on the wounds. After wounding, tissue samples from palatal mucosa were harvested at 4, 7, 14 and 21 days and then evaluated histologically.

Results: It was observed that $10 \%$ A. densiflora root extract has progressive effects on wound healing in experimental groups.

Conclusions: This study suggests that $A$. densiflora root extract could be developed as a therapeutic agent for wound healing. (Eur J Dent 2009;3:96-99)

Key words: Arnebia densiflora; Wound healing; Rat; Palatal mucosa.

\section{INTRODUCTION}

The screening of plant extracts has been of great interest to scientist for the discovery of new drugs effective in the treatment of several diseases. ${ }^{1}$ Turkish flora has one of the most extensive floras in the world with more than 9000 plant species. ${ }^{2}$

\footnotetext{
a Assistant Professor, Department of Oral and Maxillofacial Surgery, Faculty of Dentistry, Cumhuriyet University, Sivas, Turkey.

b Associate Professor, Department of Oral and Maxillofacial Surgery, Faculty of Dentistry, Gazi University, Ankara, Turkey. c Professor, Department of Biology, Faculty of Science and Literature, Karadeniz Technical University, Trabzon, Turkey.

d Professor, Department of Histology and Embryology, Faculty of Medicine, Cumhuriyet University, Sivas, Turkey.
}

A number of reports concerning the antibacterial, anti-inflammatory and wound healing activity of plant extracts of Turkish medicinal plants have appeared in the literature, but the vast majority has yet to be investigated. 3,4
Associate Professor, Department of Oral and Maxillofacial Surgery, Faculty of Dentistry, Gaziantep University, Gaziantep, Turkey.

- Corresponding author: Dr. H. Huseyin Kosger Cumhuriyet Universitesi, Dis Hekimligi Fakultesi, ADCH ve Cerrahisi AD, 58140, Sivas, Turkey. Phone: $+903462191010 / 2784$ Fax: +903462191237

E-mail: hkosgerdcumhuriyet.edu.tr 
The genus Arnebia (Boraginaceae) are represented by 4 species in the flora of Turkey, one of which, Arnebia densiflora (Nordm.) Ledeb. is widespread in Sivas district ${ }^{2}$ and known as egnik by local people and used as red colouring for dying the carpets and the rugs. ${ }^{5}$ Also, $A$. densiflora roots soaked in butter are used in local wound healing care. The roots of this plant have been reported to contain alkannin derivatives, namely $\beta, \beta$-dimethylacrylalkannin, teracrylalkannin and isovalerylalkannin + $\alpha$-methyl-n-butylalkannin. ${ }^{6}$

This study was designed to explore the healing effects of topically applied ointment prepared from A. densiflora root extracts in rat intraoral wound.

\section{MATERIALS AND METHODS}

Collection of plant material

A. densiflora plants (Boraginaceae) were collected from the Ulas, Sivas, Turkey in June. It was identified by Dr. Erol Donmez at the Department of Biology, Cumhuriyet University, Turkey. Voucher specimens have been deposited at the Herbarium of the Department of Biology, Cumhuriyet University, Turkey.

\section{Preparation of the $\mathrm{n}$-hexane extract}

The air-dried and powdered roots of $A$. densiflora were extracted with $\mathrm{n}$-hexane using Soxhlet extraction apparatus for 12 hours. The extract was concentrated under reduced pressure (yield $5.3 \% \mathrm{w} / \mathrm{w}$ ). The ointment was prepared as $10 \%(\mathrm{w} / \mathrm{w}$ ) concentration, e.g. $5 \mathrm{~g}$ of extract was incorporated in $45 \mathrm{~g}$ of ointment base (lanolin and liquid paraffin).

\section{Animals}

Wistar albino rats (200-220 gr) were used to carry out the experiment. Forty-eight animals were mainly divided to two groups (scalpel with and without extract). Each main group was divided to four subgroup containing six rats in each to observe changes after $4^{\text {th }}, 7^{\text {th }}, 14^{\text {th }}$, and $21^{\text {st }}$ days. Animals were housed in metal cages and provided with standard food and tap water ad libitum.

\section{Incision wound}

All animals were anaesthetized intramuscularly with ketamine plus xylazin combination. A $10-\mathrm{mm}$ length full-thickness incision wound was made in the mucoperiosteum of midline of the hard palate using number 15 scalpel. No medication was used throughout the experiment. After the incision was made, incised mucosa sutured with single cat gut sutures. The ointment was applied to the wound once a daily in the experimental group animals. Animals were sacrificed in $4^{\text {th }}, 7^{\text {th }}, 14$ th, $21^{\text {st }}$ days.

\section{Histopathological examinations}

After the creation of the wound, the rats were sacrificed at $4^{\text {th }}, 7^{\text {th }}, 14^{\text {th }}$ or $21^{\text {st }}$ days and the wound area excised. The tissue was fixed in $10 \%$ neutral formalin solution. The formalin-fixed tissues were dehydrated, embedded in paraffin. The 5-7 $\mu \mathrm{m}$ sections of the tissues were stained with Haematoxylin and Eosin or Mallory Azan, and evaluated for the histological changes under light microscope (Jenamed II, Carl Zeiss, Gottingen, Germany).

\section{RESULTS}

Findings on each group were evaluated and histological differences were compared between control and experimental groups of section.

At the $4^{\text {th }}$ day, no healing was observed in the

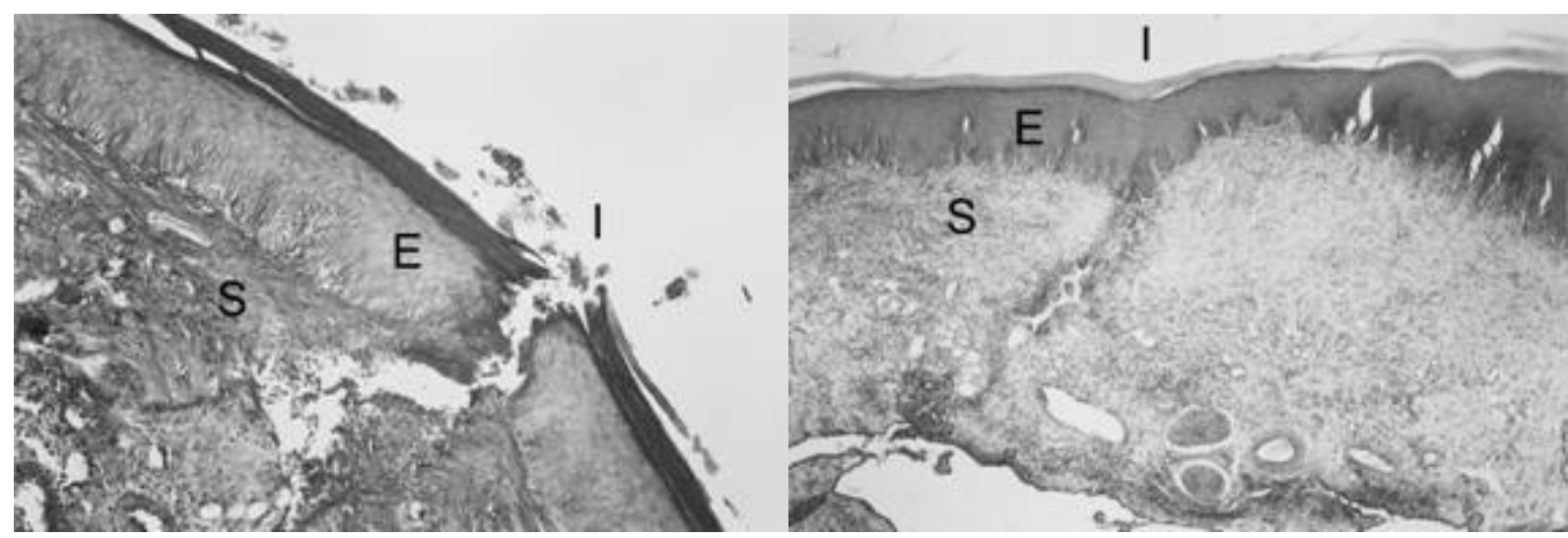

Figure 1. Illustrates the day 4 untreated (a) and A. densiflora treated (b) incisional (I) regions made by scalpel. Epithelium (E), subepithelium (S), a: MAx20, b: HEx10. 
control group. Incision region was not healed and in some animals, it was observed that mucosal closure was completed; however, submucosal closure was not. It was observed that epithelial and subepithelial regions of incision area were closed in animals treated with $A$. densiflora root extract for four days. The collagen production was in reticular fiber stage but was not completed. Mononuclear cell infiltration was present. In the experimental group, rapid improvement was determined comparing with the control group (Figure 1).

In the control group, wound was exactly closed after 7 days; collagen production was in reticular fiber stage and in this region, mononuclear cell infiltration was present. The collagen fibers were prominently observed in wound regions treated with extract for 7 days. Epithelial hyperplasia was

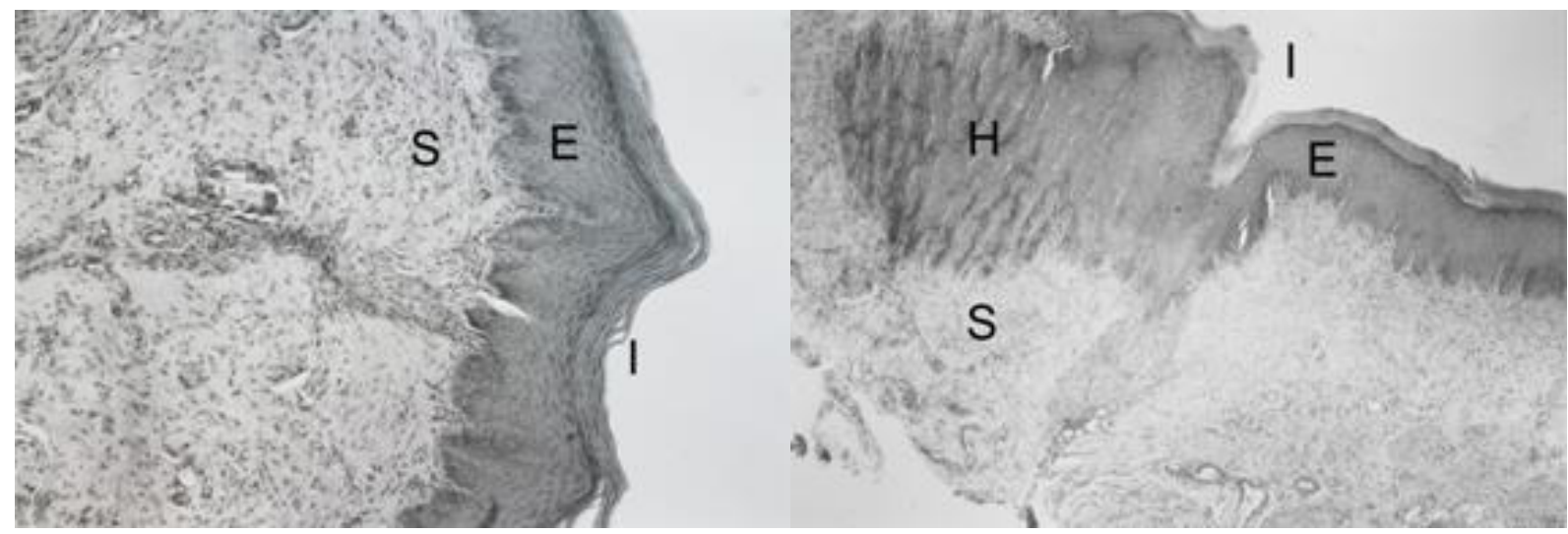

Figure 2. Seven days after scalpel incision (I), both epithelium (E) and subepithelium (S) regions seem to be healed in untreated (a) and A. densiflora treated (b) groups. Epidermal hyperplasia $(\mathrm{H})$ is also evident in the A. densiflora treated group. a: HEx20, b: HEx10.

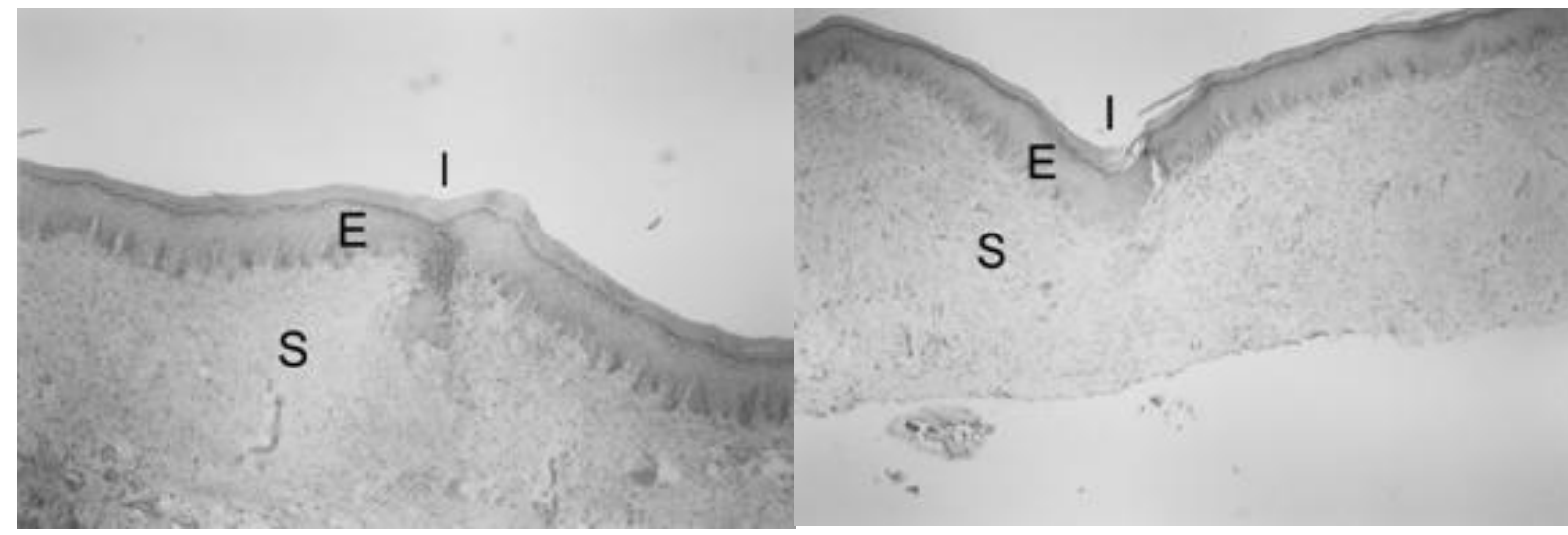

Figure 3. Shows epithelium (E) and subepithelium (S) regions 14 days after scalpel incisions (I). a: untreated, b: A. densiflora treated group. a, b: HEx10.

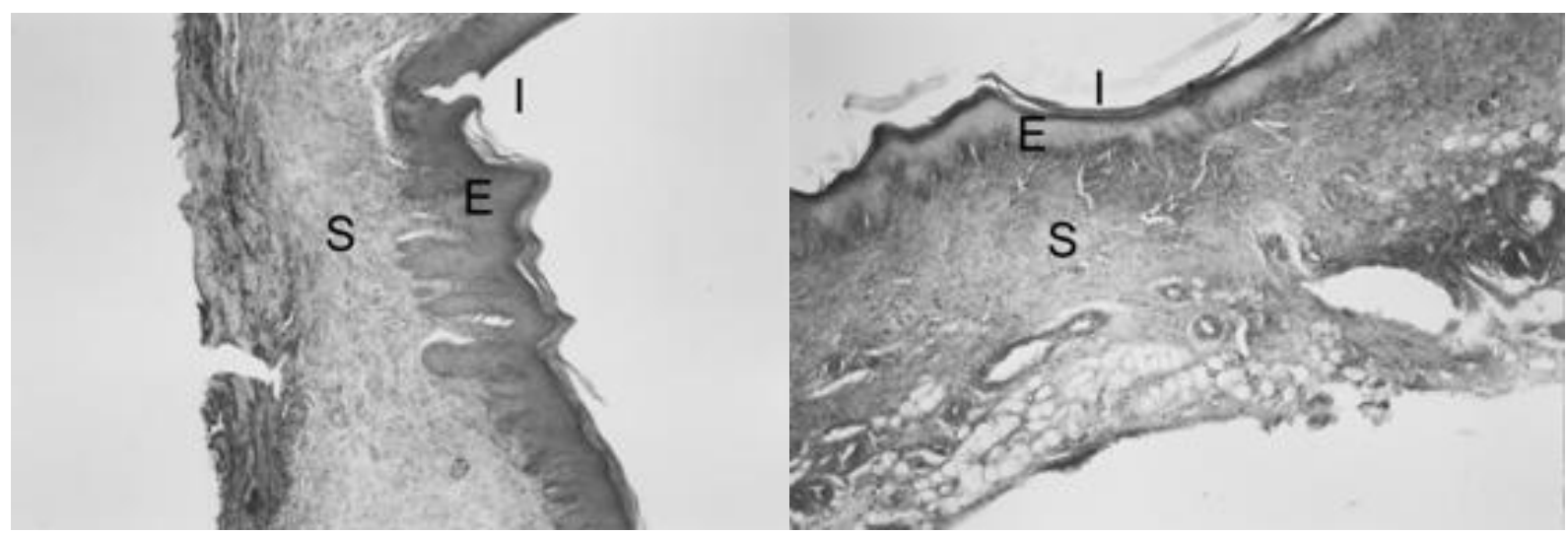

Figure 4. Epithelium (E) and subepithelium (S) regions of untreated (a) and A. densiflora treated (b) groups 21 days after scalpel incisions (I). a, b: HEx10. 
observed. Subepithelial healing was evident than that of control group (Figure 2).

After 14 days in the control group, subepithelial healing accelerated and it was seen that collagen fibers were marked. Wound healing was favorable in incision areas treated with extract during 14 days than that of controls. However, mononuclear cell infiltration was present in incision areas (Figure 3).

Twenty-one days after incision made with scalpel, it was observed that the incision area was entirely closed; and epithelium and subepithelium were normal in appearance (Figure 4).

\section{DISCUSSION}

A. densiflora is one of the four species of genus Arnebia (Boraginaceae). Previous studies showed antibacterial, anti-tumoural and wound healing activities of napthaquinone isolated from Arnebia. ${ }^{7-}$ 11 Aktan found that application of ointment containing $10 \% \mathrm{~A}$. densiflora root extract to fullthickness skin incision in rats for 7 days decreased the oedema, while collagen fibre development and epithelium regeneration accelerated thus epithelium thickness increased. ${ }^{12}$ In this study, we histologically evaluated effect of $A$. densiflora root extract on scalpel wounds in rat palatal tissue model. Rats treated with $A$. densiflora showed rapid healing than the control group. Wound closure and collagen production were faster and healing occurred on the $14^{\text {th }}$ day after wounding, however, in the control group healing was occurred on the $21^{\text {st }}$ day.

A. densiflora root extract improved healing, especially wound closure and collagen fibre production stages. However, this outcome may also show differences in human wound healing models.

\section{CONCLUSIONS}

In the limits of this study, $A$. densiflora root extract seems to improve healing of scalpel wounds in rat palatal mucosa. Also, as our study used $A$. densiflora root extract instead of isolated napthaquinone derivatives, further studies using isolated napthaquinone derivatives would be much informative.

\section{ACKNOWLEDGEMENTS}

Financial support from Cumhuriyet University (number: DIS-007) is gratefully acknowledged.

\section{REFERENCES}

1. Cragg GM, Newman DJ, Snader KM. Natural products in drug discovery and development. J Nat Prod 1997;60:5260.

2. Davis PH. Flora of Turkey and East Aegean Islands. Vol 6. University Press, Edinburgh, 1988: p. 311.

3. Sokmen A, Jones BM, Erturk M. The in vitro antibacterial activity of Turkish medicinal plants. J Ethnopharmacol 1999;67:79-86.

4. Dulger B, Gonuz A, Aysel V. Inhibition of clotrimazoleresistant Candida albicans by some endemic Sideritis species from Turkey. Fitoterapia 2006;77:404-405.

5. Baytop T. A dictionary of vernacular names of wild plants of Turkey, vol. 578. Turkish Language Society, Ankara, 1997: p. 131.

6. Bozan B, Baser KHC, Kara S. Quantitative determination of naphthoquinones of Arnebia densiflora by TLCdensitometry. Fitoterapia 1999;70:402-406.

7. Yao XS, Ebizuka Y, Noguchi H, Kiuchi H, Shibuya M, litaka $Y$, Seto H, Sankava U. Biologically active constituents of Arnebia euchroma: Structure of arnebinol, an ansatype monoterpenylbenzenoid with inhibitory activity on prostaglandin biosynthesis. Chem Pharm Bull 1991;39:29562961.

8. Kaith BS, Kaith NS, Chauhan NS. Anti-inflammatory effect of Arnebia euchroma root extract in rats. J Ethnopharmacol 1996;55:77-80.

9. Sidhu GS, Singh AK, Banaudha KK, Gaddipati JP, Patnaik GK, Maheswari RK. Arnebin-1 accelerates normal and hydrocortisone-induced impaired wound healing. J Invest Dermatol 1999;113:773-781.

10. Gaddipati JP, Mani H, Shefali, Raj K, Mathad VT, Bhaduri AP, Maheshwari RK. Inhibition of growth and regulation of IGFs and VEGF in human prostate cancer cell lines by shikonin analogue 93/637 (SA). Anticancer Res 2000;20:2547-2552.

11. Ogurtan Z, Hatipoglu F, Ceylan C. The effect of Alkanna tinctoria Tausch on burn wound healing in rabbits. Dtsch Tierarztl Wochenschr 2002;109:481-485.

12. Aktan Y. Analgesic, anti-inflammatory, wound healing activities and effects on liver of Arnebia densiflora (Nordm.) Ledeb. root extract. Institute of Health Sciences, Master Thesis, 1994, Osmangazi University, Eskisehir, Turkey lin Turkish). 